Gut, 1978, 19, 294-299

\title{
Serum and tumour ferritins in primary liver cancer
}

\author{
M. C. KEW, J. D. TORRANCE, D. DERMAN, M. SIMON, G. M. MACNAB, \\ R. W. CHARLTON, AND T. H. BOTHWELL \\ From the MRC Iron and Red Cell Metabolism Unit, Department of Medicine, University of \\ the Witwatersrand, and the School of Pathology of the South African Institute for Medical Research \\ and the University of the Witwatersrand, Johannesburg, South Africa
}

SUMMARY Serum ferritin concentrations were found to be raised, often considerably, in 58 of 76 black patients with primary liver cancer (PLC). No correlation could be demonstrated between the serum ferritin concentration and several other measurements, including the following: hepatic iron stores measured chemically, the size of the tumour, serum transaminase values, and the presence or absence of cirrhosis in the non-tumorous liver. There was, however, a negative correlation between serum ferritin and alpha-foetoprotein concentrations. Ferritin was purified from PLC tissue obtained from three patients at necropsy and the distribution of isoferritins was determined by isoelectric focusing. Acidic isoferritins similar to those previously found in PLC tissue were obtained. Their acidic nature was confirmed chromatographically using DEAE cellulose. Because the serum ferritin in patients with PLC probably consists of a mixture of normal and acidic isoferritins, it is likely that the serum ferritin assay used in the present study underestimated the actual concentrations present. With the development of an assay which utilises a specific antibody against acidic PLC isoferritins, serum ferritin may prove to be a second marker for PLC.

Storage iron exists in two forms which are closely related both functionally and structurally: the diffuse soluble fraction is called ferritin and the aggregated insoluble fraction, haemosiderin. With the development of sensitive immunoradiometric assays for ferritin, it has become apparent that small amounts are normally present in serum (Jacobs et al., 1972) and that the concentrations closely mirror the size of the iron stores in the body (Walters et al., 1973). There are, however, conditions in which this relationship does not hold. Inappropriately high concentrations may occur in infections, in acute and chronic liver diseases, in various haemolytic states, and in a number of neoplastic disorders, including leukaemias, lymphomata, and solid tumours (Jacobs and Worwood, 1975).

Of particular interest has been the finding of raised serum ferritin concentrations in some patients with primary liver cancer (PLC). The reason for this is not known, but four possible mechanisms warrant consideration. Firstly, necrosis of liver cells caused

${ }^{1}$ Address for correspondence and reprint requests: Dr M. C. Kew, Department of Medicine, Witwatersrand University Medical School, Hospital Hill, Johannesburg, 2001, South Africa.

Received for publication 2 November 1977 by growth of the tumour could result in leakage of storage ferritin into the serum. As in other forms of liver damage, the quantity would depend upon both the severity of the hepatic injury and the amount of iron stored in the liver (Prieto et al., 1975). Secondly, serum ferritin concentrations are known to be raised in cryptogenic cirrhosis (Prieto et al., 1975), which is frequently found in association with PLC (MacDonald, 1956). Increased serum ferritin levels in PLC might therefore be attributable to the cirrhosis rather than to the tumour per se. A third possible reason might be impaired hepatic uptake of serum ferritin by the diseased liver, since there is experimental evidence that virtually all circulating ferritin is cleared by the liver (Lipschitz et al., 1971). The fourth, and perhaps the most likely explanation, is that the tumour secretes ferritin or a ferritin variant (isoferritin) into the circulation. While isoferritins have been demonstrated in human PLC tissue (Alpert et al., 1973; Niitsu et al., 1975), it is not known whether they account for the raised serum ferritin concentrations.

The purpose of the present study was to measure serum ferritin concentrations in patients with PLC and to determine whether they were related to the extent of liver cell damage, to the presence or absence of cirrhosis, to the hepatic storage iron 
content, and to the size of the tumour. As these tumours frequently produce alpha-foetoprotein (AFP), and because ferritin may prove to be a second serological marker of PLC, we compared serum ferritin and AFP concentrations in a number of patients. In addition, ferritin was purified from PLC tissue obtained trom three patients at necropsy, from non-tumorous and non-cirrhotic liver tissue from one of these patients, and also from normal liver and spleen. The distribution of isoferritins was then determined by isoelectric focusing.

\section{Methods}

All but one of the 76 black patients with histologically proven PLC were males. Their ages ranged from 20 to 56 years with a mean of 36 years. Before starting treatment, serum was collected for the estimation of the ferritin concentration by radioimmunoassay (Miles et al., 1974) using normal human liver ferritin as the antigen. In 44 unselected patients glutamic oxaloacetic (GOT) and glutamic pyruvic (GPT) transaminase activities were also determined, and in 32 unselected patients, the AFP concentrations were measured by radioimmunoassay (Ruoslahti and Seppälä, 1971). In 32 patients hepatic scintiscans were performed using ${ }^{99 m}$ technetium sulphur-colloid, and an estimate of the size of the tumour was obtained by measuring the percentage area of the defect or defects on the anterior scan with a planimeter. The non-haem iron concentration in non-tumorous liver tissue obtained at necropsy was determined chemically in 17 patients (Torrance and Bothwell, 1968) and the iron stores were also assessed histologically, using the following criteria (Bothwell and Bradlow, 1960).

\section{CRITERIA OF ASSESSMENT}

\section{Parenchymal cells}

Grade $\mathbf{0}$ indicates no stainable iron granules; grade + indicates a few small fine granules of haemosiderin usually confined to the biliary pole in some, or most, of the liver cells, especially in the periportal regions; grade ++ indicates numerous fine granules of haemosiderin in most of the cells, and grade +++ indicates numerous coarse granules of haemosiderin in most of the liver cells.

\section{Kupffer cells}

Grade $\mathbf{0}$ indicates no stainable haemosiderin granules; grade + indicates occasional fine haemosiderin granules in some of the Kupffer cells; grade ++ indicates numerous fine haemosiderin granules in most of Kupffer cells; and grade +++ indicates numerous coarse haemosiderin granules in most of the Kupffer cells. (With grade +++ the Kupffer cells were usually markedly enlarged.)

Portal tract macrophages,$\because \cdot$

Grade 0 indicates no stainable haemosiderin granules; grade + indicates occasional fine haemosiderin granules in portal tract macrophages; grade ++ indicates small clumps of macrophages containing fine and coarse haemosiderin granules; and grade +++ indicates coarse, irregular, intra- and extracellular masses of haemosiderin. In 50 subjects the presence or absence of cirrhosis was established at necropsy.

As it has been shown that the serum ferritin concentrations of a population are normally distributed after logarithmic transformation (Cook et al., 1974), this was done before correlating them with the chemical and histological estimates of hepatic storage iron, the size of the tumour, the presence or absence of cirrhosis, and the serum transaminase and AFP concentrations. Parametric statistical methods were used except for the correlations between ferritin and AFP and between ferritin and histological storage iron concentrations. In these latter instances Spearman ranking was employed.

Tumour tissue was obtained at necropsy within 60 minutes of death from three patients with PLC, and liver and splenic tissue from a male black patient with dietary siderosis but no PLC or cirrhosis. The tissues were stored at $-20^{\circ} \mathrm{C}$ until the ferritin was extracted and the extracted ferritin was then kept at $4^{\circ} \mathrm{C}$.

\section{PREPARATION OF FERRITIN}

Two methods were used to purify ferritin from normal liver and from PLC tissue. With both techniques the tissue was homogenised in four volumes of water and heated for 10 minutes at $75^{\circ} \mathrm{C}$. After cooling, the coagulated material was removed by centrifugation, and the $\mathrm{pH}$ of the supernatant was adjusted to 4.8 using dilute acetic acid. Any precipitate which formed overnight at $4^{\circ} \mathrm{C}$ was removed by centrifugation. With the first method (Mazur and Shorr, 1948), further purification was achieved by crystallisation of the ferritin by the addition of 0.25 volumes of $20 \%$ cadmium sulphate. The crystals were redissolved in $2 \%$ ammonium sulphate and recrystallised with cadmium sulphate. Five crystallisations were carried out, followed by five precipitations of the ferritin by either $50 \%$ or $70 \%$ ammonium sulphate. In some cases this product was further purified using a $1.6 \times 90 \mathrm{~cm}$ column of Sephacryl A200.

The second method of purification was based on the scheme of Drysdale and Munro (1965). The pH 4.8 supernatant was applied directly to a column of 
CM cellulose (Whatman CM 52) which had been equilibrated to $\mathrm{pH} 4.8$ with acetate buffer containing $15 \mathrm{mM}$ sodium acetate and $10 \mathrm{mM}$ acetic acid. The column was washed with this buffer and with a buffer containing $32 \mathrm{mM}$ sodium acetate and $18 \mathrm{mM}$ acetic acid. The ferritin was then eluted with acetate buffer pH 5.5 containing 32.8 acetate and $6.2 \mathrm{mM}$ acetic acid.

The ferritin fraction was dialysed against $10 \mathrm{mM}$ tris- $\mathrm{HCl} \mathrm{pH} 8$ and applied to a $20 \times 1.5 \mathrm{~cm}$ DEAE cellulose column (Whatman DE 52) equilibrated with the same buffer. The column was eluted with a linear $0-0.25 \mathrm{M}$ sodium chloride gradient. Fractions containing ferritin were pooled and precipitated with $70 \%$ ammonium sulphate. The precipitate was dissolved in a minimum volume of $0.9 \%$ sodium chloride and chromatographed on a $90 \times 1.6 \mathrm{~cm}$ Sephacryl 200 column.

\section{ISOELECTRIC FOCUSING}

The ferritin samples were focused in an LKB $110 \mathrm{ml}$ iso-focusing column following the instructions of the manufacturer. LKB ampholine pH range 4-6 was used in a sucrose gradient. The cathode was at the bottom of the column. The column was run at $500 \mathrm{~V}$ for 48 hours by which time the current was always less than $1 \mathrm{~mA}$. A Uvicord II was used to monitor the optical density of the column as it was drained. The $\mathrm{pH}$ of each fraction was read immediately using a combined electrode (Radiometer GK2301B).

\section{Results}

Serum ferritin concentrations ranged from $30 \mu \mathrm{g} / \mathrm{l}$ to $25,600 \mu \mathrm{g} / \mathrm{l}$, with a median value of $800 \mu \mathrm{g} / \mathrm{l}$ and a geometric mean of $845 \mu \mathrm{g} / 1$ (the value for +2 standard errors of the geometric mean was $1193 \mu \mathrm{g} / \mathrm{l}$ and for -2 standard errors, $598 \mu \mathrm{g} / \mathrm{l})$. In 18 of the patients the concentrations were within the normal range (less than $300 \mu \mathrm{g} / \mathrm{l}$ ). The distribution of the individual values is shown in Fig. 1 .

There was a significant correlation $\left(r_{\mathrm{s}} \mathbf{0} 8036\right.$, $P<0.01)$ between the hepatic non-haem iron concentrations and the histological assessments of liver storage iron, which are given with the serum ferritin concentrations in the Table. The correlation between the serum ferritin concentrations and the hepatic non-haem iron concentrations was not significant $(r+0.3266, \mathrm{P}>0.05)$, but that between the serum ferritin concentrations and the liver iron stores as assessed histologically was significant by the non-parametric test $\left(r_{\mathrm{s}}+0.5621, \mathrm{P}<0.05\right)$.

On planimetric analysis of the anterior scintiscan the tumour comprised from $5 \%$ to $60 \%$ of the liver. There was no correlation between the serum ferritin

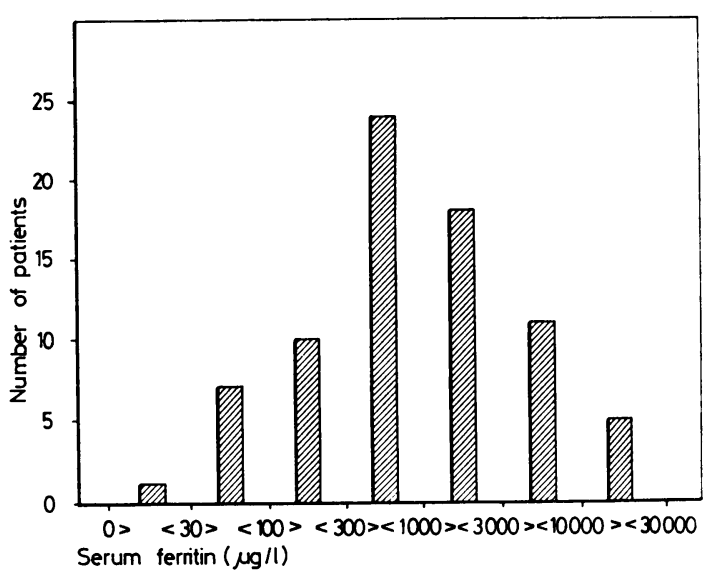

Fig. 1 Distribution of serum ferritin concentrations, using equal intervals on a logarithmic scale, in 76 patients with primary liver cancer.

concentrations and the size of the tumour estimated in this way $(r-0.3456, \mathrm{P}>0.05)$.

There was also no correlation between the serum ferritin level and the serum GOT $(r+0 \cdot 1017)$ or GPT $(r-0.0036)$ activities. Macronodular cirrhosis was present in 17 of the 50 patients examined at necropsy. When the serum ferritin levels in these patients were compared with those in the 33 patients without cirrhosis, no differences in the range or geometric mean $( \pm$ standard errors) were found $(t 0.77, \mathrm{P}>0.05)$. None of these patients showed the histological features of alcoholic liver disease.

There was a negative correlation between the serum ferritin and the serum AFP levels $\left(r_{s}-0.3652\right.$, $P<0.05$ ) (Fig. 2).

\section{ISOLATION AND ISOELECTRIC FOCUSING PATTERNS OF FERRITIN ISOLATED FROM NORMAL LIVER AND PLC TISSUE}

Ferritin was isolated by the method of Mazur and Shorr (1948) from liver and spleen tissue obtained at necropsy from an iron over-loaded black male with no PLC. On isoelectric focusing four or five isoferritin peaks with $\mathrm{pI}$ values between $\mathrm{pH} 5 \cdot 0$ and $5 \cdot 5$ could be seen in each case. Ferritin was also prepared by the method of Drysdale and Munro (1965) from PLC tissue and from non-tumorous and noncirrhotic liver tissue obtained from a single patient. The liver ferritin pattern after isoelectric focusing was similar to that of the normal liver ferritin, with peaks at pH $5 \cdot 02,5 \cdot 18,5 \cdot 25$ and $5 \cdot 32$, and $5 \cdot 42$ (Fig. 3). The PLC ferritin from the same liver gave a different isoferritin pattern, the pI values of the peaks being $4 \cdot 8,4 \cdot 86,4.9$ and 4.95 , with a smaller 
Table Comparison of serum ferritin concentrations with non-haem iron concentrations assessed chemically and histologically in non-tumorous liver tissue in 17 patients with primary liver cancer

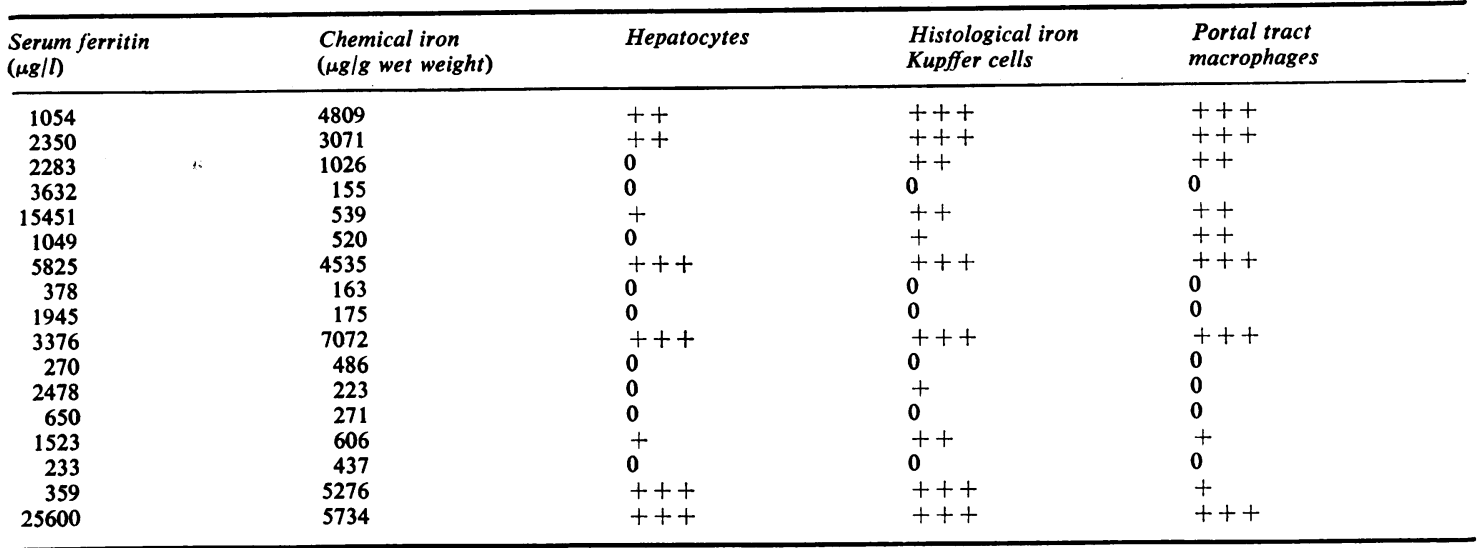

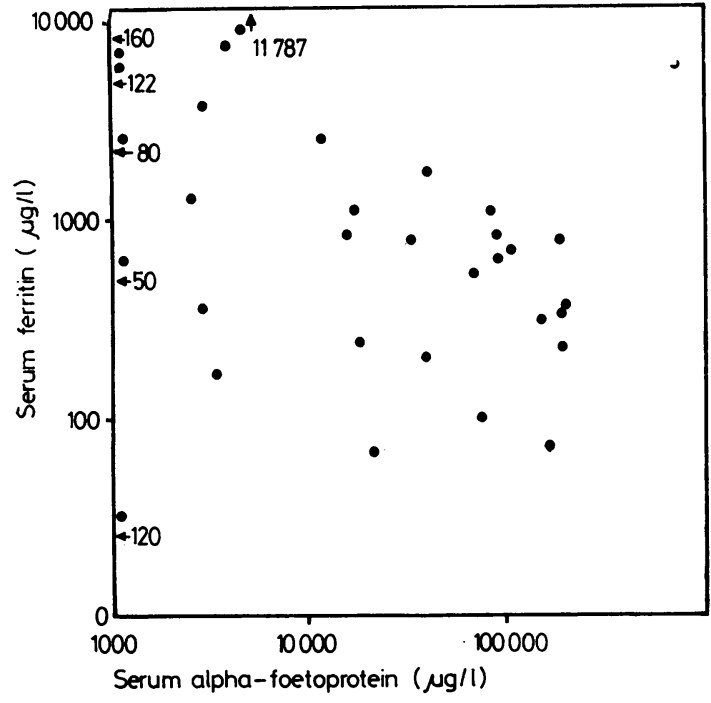

Fig. 2 Inverse correlation between serum ferritin and alpha-foetoprotein concentrations in 32 patients with primary liver cancer $\left(r_{8}-0.3652, \mathrm{P}<0.05\right)$.

peak at $5 \cdot 12$ (Fig. 3 ). That the PLC isoferritins were more acidic than the normal liver isoferritins was also evident during DEAE cellulose chromatography. The normal liver ferritin was eluted from a $\mathrm{pH} 8.0$ DEAE cellulose column by $0.02 \mathrm{M}$ sodium chloride, while $0.01 \mathrm{M}$ sodium chloride was required to elute PLC ferritin. In the second patient in whom ferritin was extracted from PLC tissue using the same procedure, a similar isoferritin pattern was obtained, with peaks corresponding to $\mathrm{pH}$ values of $4 \cdot 56$, $4 \cdot 66$, and $4 \cdot 8$. In a third patient two distinct groups of peaks were obtained, the first at $\mathrm{pH} 4 \cdot 57,4 \cdot 61$,

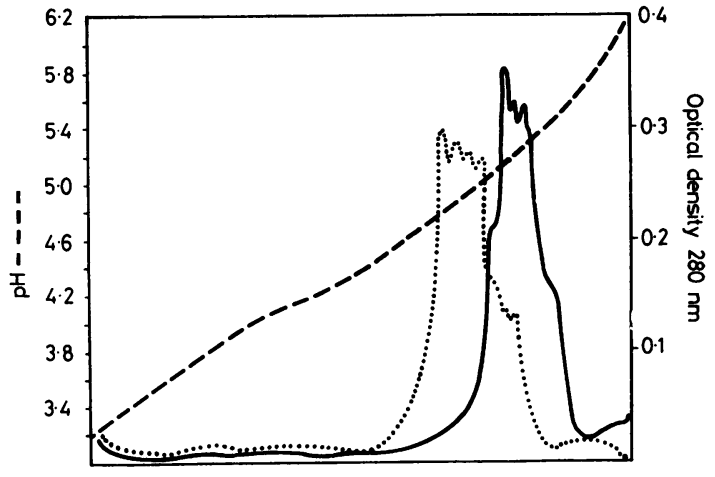

Fig. 3 Isoferritin patterns obtained by electrofocusing PLC ferritin (. . .) and liver ferritin (-) from a single patient dying from primary liver cancer.

$4 \cdot 64$, and $4 \cdot 73$, and the second corresponding to the normal liver isoferritin pattern, with peaks at pH $5 \cdot 09,5 \cdot 18,5 \cdot 30$, and $5 \cdot 32$. In this last patient the tumour was of the diffusely infiltrating variety, and it is possible that the PLC tissue analysed contained some non-malignant liver tissue.

\section{Discussion}

This study has shown that serum ferritin concentrations are frequently raised in black patients with PLC. Similar findings have been reported in smaller series of patients in Japan (Niitsu et al., 1975) and elsewhere (Powell et al., 1975), although the values in our patients were often considerably higher than those previously described. Since it could be argued that the high serum ferritin concentrations in our patients were merely a reflection of the increased 
body iron stores that are so common in South African blacks (Bothwell and Finch, 1962), an attempt was made to relate them to hepatic iron stores as estimated both chemically and by semiquantitative histological grading. Some correlation was noted between the serum ferritin concentrations and the histological assessments of hepatic iron stores, but it did not reach statistical significance when the more accurate chemical estimations of non-haem iron in the liver were used. While siderosis may, therefore, be one of the factors contributing to the high serum ferritin concentrations in these patients, it seems unlikely to be the major explanation. In any event, high serum ferritin concentrations have been noted in association with PLC in populations in which iron overload is extremely rare (Niitsu et al., 1975).

Raised serum ferritin concentrations have also been described in patients with cryptogenic cirrhosis (Prieto et al., 1975), a condition which frequently occurs in association with PLC in this population (Kew et al., 1974). The values were not, however, higher in the PLC patients in whom cirrhosis was present than in those in whom it was not. Moreover, the serum ferritin concentrations in cirrhosis without PLC have usually been only moderately raised (Prieto et al., 1975), whereas they were strikingly raised in many of our patients.

If increased serum ferritin levels in PLC were due to leakage of stored ferritin from necrotic hepatocytes at the growing edge of the tumour, it seems reasonable to expect a positive correlation with an index of liver cell damage such as the serum transaminases, and with the size of the tumour as well as with the amount of iron stored. In no instance, however, could such a correlation be found. While it is known that the growth rate of PLC in these patients can be extremely rapid, with an estimated doubling time of about 10 days, the possibility that this might be a factor was not assessed in the present study.

Decreased hepatic uptake of circulating ferritin as a cause of the raised serum ferritin concentrations is less easy to test. However, it was thought that this mechanism was unlikely, as liver function was well maintained in our patients until the terminal phases of the illness.

It therefore seems probable that the raised serum ferritin concentrations in PLC were largely due to the production and secretion of specific isoferritins by the tumour itself. Powell and coworkers (1975) have found that serum from a patient with PLC contained acidic isoferritins in addition to the more basic isoferritins normally found in serum. These acidic isoferritins correspond approximately to the isoferritins which have been purified from PLC tissue.
Such isoferritins, which occur in addition in normal heart and have been reported in other tumours such as breast and pancreatic neoplasms (Marcus and Zinberg, 1975; Alpert, 1975), were also found to be present in PLC tissue from our patients. Niitsu and coworkers (1975) have found that the concentration of isoferritins in PLC tissue is lower than that in non-tumorous liver tissue, and that they have a lower iron content. This suggests that the isoferritins synthesised by the tumour do not accumulate in the neoplasm but are secreted into the circulation.

The presence of these isoferritins in the serum complicates the measurement of serum ferritin concentrations using immunological techniques. Hazard and his colleagues (1977) have produced two antibodies to ferritin, one of which combines preferentially with basic and the other with acidic isoferritins. Using the basic antibody they have demonstrated that their radioimmunoassay for serum ferritin, which employs liver ferritin as antigen, overestimates the serum concentrations in normal and iron overloaded subjects. This they have ascribed to the fact that the isoferritins found in serum are even more basic than most liver isoferritins. On the other hand, serum ferritin concentrations might be underestimated by as much as two orders of magnitude if the serum contained only acidic isoferritins, as such isoferritins have only low reactivities with basic ferritin antibodies. Because the serum ferritin in subjects with PLC probably consists of both normal and acidic isoferritins, it is possible that results obtained in the present and other studies in which liver was used as the source of the antigen have underestimated the actual concentrations present.

As an isoferritin similar to that found in PLC tissue has been isolated from foetal liver (Alpert et al., 1973), it is conceivable that isoferritin production by the tumour represents a retrodifferentiation or dedifferentiation of function of the malignant hepatocyte, in much the same way as has been postulated to explain the production of AFP by PLC. Like the serum ferritin concentration, the AFP concentration is not related to the size of the tumour. Furthermore, considerably raised serum AFP levels are found in southern African blacks with PLC (Kew, 1974). In view of these similarities, our finding of a negative correlation between serum ferritin and AFP concentrations is of interest, and may also have practical implications. AFP is used as a diagnostic marker of PLC, but false-negative results are not infrequent, particularly in those parts of the world where the tumour is uncommon. The finding of high serum ferritin concentrations in such patients would make the likelihood of PLC much greater, even without the development of an assay 
utilising PLC isoferritins as the antigen. If the latter assay is developed it would provide a precise second marker for PLC which could be of particular value in recognising early cases of PLC, where the AFP estimation has been disappointing (Masseyeff, 1973; Purves, 1973).

The authors acknowledge with gratitude support from the South African Atomic Energy Board and the National Cancer Association of South Africa.

\section{References}

Alpert, E. (1975). Characterization and subunit analysis of ferritin isolated from normal and malignant human liver. Cancer Research, 35, 1505-1509.

Alpert, E., Coston, R. L., and Drysdale, J. W. (1973). Carcino-foetal human liver ferritins. Nature (Lond.), 242, 194-196.

Bothwell, T. H., and Bradlow, B. A. (1960). Siderosis in the Bantu. A combined histopathological and chemical study. Archives of Pathology, 70, 279-292.

Bothwell, T. H., and Finch, C. A. (1962). Iron Melabolism. Little, Brown: Boston.

Cook, J. D., Lipschitz, D. A., Miles, L. E. M., and Finch, C. A. (1974). Serum ferritin as a measure of iron stores in normal subjects. American Journal of Clinical Nutrition, 27, 681-687.

Drysdale, J. W., and Munro, H. N. (1965). Small-scale isolation of ferritin for the assay of the incorporation of ${ }^{14} \mathrm{C}$-labelled amino acids. Biochemical Journal, 95, 851-858.

Hazard, J. T., Yokota, M., Arosio, P., and Drysdale, J. W. (1977). Immunologic differences in human isoferritins: implications for immunologic quantitation of serum ferritin. Blood, 49, 139-146.

Jacobs, A., Miller, F., Worwood, M., Beamish, M. R., and Wardrop, C. A. J. (1972). Ferritin in the serum of normal subjects and patients with iron deficiency and iron overload. British Medical Journal, 4, 206-208.

Jacobs, A., and Worwood, M. (1975). Fenitin in serum. Clinical and biochemical implications. New England Journal of Medicine, 292, 951-956.

Kew, M. C. (1974). Alpha-fetoprotein in primary liver cancer and other diseases. Gut, 15, 814-821.

Kew, M. C., Geddes, E. W., Macnab, G. M., and Bersohn, I. (1974). Hepatitis-B antigen and cirrhosis in Bantu patients with primary liver cancer. Cancer, 34, 539-541.
Lipschitz, D. A., Dugard, J., Simon, M. O., Bothwell, T. H., and Charlton, R. W. (1971). The site of action of desferrioxamine. British Journal of Haematology, 20, 395-404.

MacDonald, R. A. (1956). Cirrhosis and primary carcinoma of the liver: changes in their occurrence at the Boston City Hospital 1897-1954. New England Journal of Medicine, 255, 1179-1183.

Marcus, D. M., and Zinberg, N. (1975). Measurement of serum ferritin by radioimmunoassay: results in normal individuals and patients with breast cancer. Journal of the National Cancer Institute, 55, 791-795.

Masseyeff, R. F. (1973). Factors affecting alpha-fetoprotein biosynthesis in patients with primary liver cancer and other diseases. Gann Monographs on Cancer Research, 14, 3-18.

Mazur, A., and Shorr, E. (1948). Hepatorenal factors in circulatory homeostasis. IX. The identification of the hepatic vasodepressor substance, VDM, with ferritin. Journal of Biological Chemistry, 176, 771-787.

Miles, L. E. M., Lipschitz, D. A., Bieber, C. P., and Cook, J. D. (1974). Measurement of serum ferritin by a 2-site immunoradiometric assay. Analytical Biochemistry, 61, 209-224.

Niitsu, Y., Ohtsuka, S., Kohgo, Y., Watanabe, N., Koseki. J., and Urushizaki, I. (1975). Hepatoma ferritin in the tissue and serum. Tumor Research, 10, 31-41.

Powell, L. W., Halliday, J. W., and McKeering, L. V. (1975). Studies of serum ferritin with emphasis on its importance in clinical medicine. In Proteins of Iron Storage and Transport in Biochemistry and Medicine, pp. 215-221. Edited by R. R. Crichton. North-Holland: Amsterdam. Elsevier: New York.

Prieto, J., Barry, M., and Sherlock, S. (1975). Serum ferritin in patients with iron overload and with acute and chronic liver diseases. Gastroenterology, 68, 525-533.

Purves, L. R. (1973). Primary liver cancer as a possible short duration seasonal cancer. South African Journal of Medical Science, 69; 173-178.

Ruoslahti, E., and Seppälä, M. (1971). Studies of carcinofetal proteins. III. Development of a radioimmunoassay for $\alpha$-fetoprotein. Demonstration of $\alpha$-fetoprotein in serum of healthy human adults. International Journal of Cancer, 8, 374-383.

Torrance, J. D., and Bothwell, T. H. (1968). A simple technique for measuring storage iron concentrations in formalinised liver samples. South African Journal of Medical Science, 33, 9-11.

Walters, G. O., Miller, F. M., and Worwood, M. (1973). Serum ferritin concentration and iron stores in normal subjects. Journal of Clinical Pathology, 26, 770-772. 